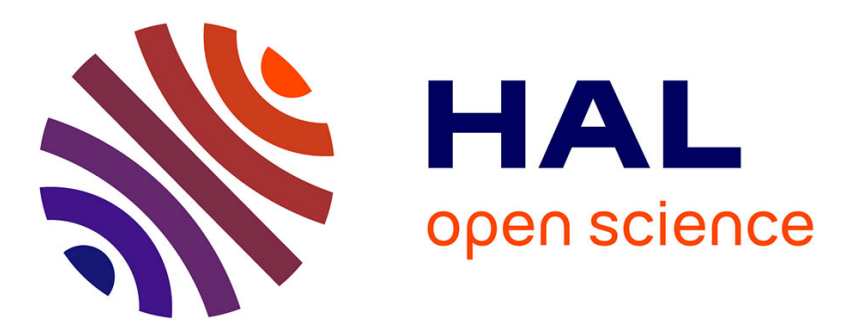

\title{
Beginnings of a new science. D'Alembert's Traité de dynamique and the French Royal Academy of Sciences around 1740
}

Christophe Schmit

\section{- To cite this version: \\ Christophe Schmit. Beginnings of a new science. D'Alembert's Traité de dynamique and the French Royal Academy of Sciences around 1740. Centaurus, 2017, 59 (4), pp.285-299. 10.1111/1600- 0498.12167 . hal-02904848}

\section{HAL Id: hal-02904848 \\ https://hal.science/hal-02904848}

Submitted on 22 Jul 2020

HAL is a multi-disciplinary open access archive for the deposit and dissemination of scientific research documents, whether they are published or not. The documents may come from teaching and research institutions in France or abroad, or from public or private research centers.
L'archive ouverte pluridisciplinaire HAL, est destinée au dépôt et à la diffusion de documents scientifiques de niveau recherche, publiés ou non, émanant des établissements d'enseignement et de recherche français ou étrangers, des laboratoires publics ou privés. 


\title{
Beginnings of a New Science. D'Alembert's Traité de dynamique and the French Royal Academy of Sciences around 1740
}

\author{
Christophe Schmit, \\ "Beginnings of a new science. D'Alembert's Traité de dynamique \\ and the French Royal Academy of Sciences around 1740", \\ Centaurus, vol. 59, Issue 4, 2017, p. 295-299
}

\begin{abstract}
D'Alembert began on the scientific European scene with the publication of his first book: the Traité de dynamique (1743). Dynamics is born in the 1730's and with the Traité D'Alembert became one of the main protagonists of that new science. Unfortunately, historians have neither manuscripts nor letters at their disposal, which could inform about the circumstances in which this book was written. The present article aims to precise those circumstances and to give essential characteristics of D'Alembert's dynamics, in particular in the light of the works led by his colleagues of the French Royal Academy of Sciences. In reading D'Alembert's ideas about causality and the proofs of some mechanical principles, in searching how he could have known some mechanical problems which appeared in the Academy around 1740, and in analyzing how he solved them, it's possible to sketch hypothesis about the formation of the young man. They involve exchanges or competition with his colleagues who probably made him discover some mechanical problems. But D'Alembert published in 1743 the first book exclusively dedicated to that science with an original and specific approach which he kept during all his scientific career, an approach that allowed him to write that his work had nothing in common with that of the others.
\end{abstract}

\section{Introduction: corpus and historiography}

The aim of this paper is to bring out the specificities of D'Alembert's dynamics by reconsidering them in the context of the work being carried out at the Royal Academy of Sciences in Paris between 1735 and 1743. Our corpus includes studies by members of the Academy during this period, such as Alexis Claude Clairaut (1713-1765), Pierre Louis Moreau de Maupertuis (1698-1759), Etienne Mignot de Montigny (1714-1782), Patrick d'Arcy (1725-1779), Alexis Fontaine des Bertins (1704-1771) and Jean Le Rond D'Alembert. Underpinning the choice of this corpus and periodisation is a common purpose in evidence during those years, both in the type of problems being studied and in their formulations expressing the principles of dynamics, homogeneity which does not last beyond $1743 .{ }^{1}$ What should we understand here by "dynamics" and what type of problems does it entail? Clairaut $(1739$, p. 3) states

a Class of Physico-mathematical Problems, the aim of which is to calculate the motions that occur to several bodies as they trace or follow certain lines - whether they move freely under the force of an initial impulsion or by accelerative forces such as gravity - when these bodies are linked together by string \& they act reciprocally one on the other in a way that alters their motion.

D'Alembert (1743, p. xxiij) employs the term "dynamics" in the title of his treatise to "notify his fellow Geometers" of the content, specifying that "over the last few years, the most accomplished Geometers have dedicated themselves to this subject", proof that the word defined as "the Science of the Motion of Bodies, acting on one another in whatever manner" is the shared property of a community. These bodies act mutually "either by pushing or pulling each other by means of some body placed between them and to which they are attached, such as a cord, an inflexible lever, a plane, etc." (D'Alembert, 1755, p. 174b). ${ }^{2}$

During this period there were profound mutations in mechanics, characterized by the emergence of new types of problems and the elaboration of new principles. ${ }^{3}$ Very little 
research has been carried out into the work done by members of the Academy ${ }^{4}$ as a whole, and although D'Alembert has been the subject of several studies ${ }^{5}$, there has been no previous attempt to contextualize his dynamics alongside those of his fellow Academicians. ${ }^{6}$ Their contribution, however, should not be overlooked: D'Alembert (1743) published the first treatise specifically dedicated to dynamics and Clairaut (1745) provided the first major overview of the question in the form of a memoir. ${ }^{7}$ Moreover, it is highly probable that D'Alembert was introduced to dynamical problems through his exchanges with colleagues whom he seemed to emulate as well as compete with. The different formulations of principles and solutions to problems therefore deserve analysis, both to underline the similarities in their approaches, and to explore the nature of their divergences. ${ }^{8}$

H. Bos (1980, pp. 333-341) observes that the history of rational mechanics is defined by C. Truesdell as being that of "the axiomatic mathematical science of mechanics". This science was to develop around two general and independent axioms, the fundamental principle of dynamics (or linear momentum) and the principle of angular momentum (or moment of momentum), applicable to discrete and continuous mechanical systems. The search for the formulation of these two axioms is, for Truesdell, the analytical instrument with which he explores an abundant corpus, leading him to draw some fundamental conclusions concerning Euler. But, following this methodology, the savants who do not develop this axiomatic or whose formulations are judged insufficiently clear or general remain in the shadow of Euler. In addition, Truesdell excludes from this history what, in the foundations of the concepts and principles, is metaphysical in nature (Bos, 1980, pp. 340-341; Boudri, 2002, pp. 12-13). A. Firode (2001, pp. 9-10) has shown that D'Alembert's principle (1743, pp. 49-51) is not "philosophically neutral" and that its technical and philosophical aspects are inseparable by nature. In the wake of this latter thesis, we will set about showing that (D'Alembert 1743) constitutes a rupture in academic practice that can only be fully appreciated by simultaneously taking into account both of these dimensions. We will underline the stances taken by D'Alembert as regards the choice of certain principles and show how different choices of axiomatization lead to specific problem-solving techniques and, in turn, how analysing the latter brings to light different epistemologies.

\section{The Academic Context: the problems}

On 24 November 1742, D'Alembert began to read his "memoir on a general Principle to find the motion of several bodies which act on one another", a reading he would pursue until 27 February 1743 at which date the mention of the word "Treatise" appeared: "Mr D'Alembert continues the reading of his Memoir or Treatise on the action of Bodies" ${ }^{\text {. At the }}$ end of the year 1740, Clairaut set a date in 1741 to begin his reading of a memoir ("On a Principle to help solve a large number of Problems in Dynamics") which he wished to publish in the Academy's 1740 volume of memoirs; at the end of 1741 we can find the same notice announcing a forthcoming reading in 1742 of a memoir with the same title. ${ }^{10}$ It did not appear in the volumes covering the years 1740 and 1741, and Clairaut once again set a date at the end of 1742 for a reading in 1743 of "On some principles to help solve a large number of problems in Dynamics", to be published in the 1742 volume. The reading finally began on 2 March 1743 and finished on 6 April 1743 at which date the Academy's records contain (Clairaut, 1745) in its entirety. ${ }^{11}$ In the mean time, D'Alembert asked on the Academy on 6 March 1743 to arrange for commissioners to examine a book "the greater part of which he [had] already read during the previous assemblies under the title Treatise on the Motion of Bodies" and had the permanent secretary of the Academy inscribe his initials on "twelve little notebooks containing the second part of the work" 12 . 
The title of the November 1742 "memoir" is similar to the title of the second part of the Traité which begins by setting out the principle (D'Alembert, 1743, p. 49) and includes fourteen problems in dynamics: the work "already read for the greater part" would seem to correspond to this part. In their report, the commissioners who examined the book, wrote:

we do not consider it necessary to review once again the major part of this work which contains the most elegant solutions to the most difficult Problems [...] deduced from one Principle alone [...] When we had finished rereading this part, our assessment was not different to the one the Academy manifested when the author [D'Alembert] gave a reading of the work himself [...] As for the first part in which Mr D'Alembert studies and explains the three principles of Dynamics and Statics [...] having explained the principles of these Sciences with the same degree of clarity and depth as he had applied to the resolution of the most complicated Problems, Mr D'Alembert has been equally successful (RMAS, 22 juin 1743, p. 280).

The content of the first part would seem to be new while the second part was already known. From this it would follow that the "little notebooks" corresponded to the problems exposed in his public reading and the signature D'Alembert requested was a way of establishing precedence over Clairaut. ${ }^{13}$ The reading given by the latter no doubt pushed him to make this request and, conversely, D'Alembert's presentation may have forced Clairaut to finally propose this memoir that had already been deferred several times. After setting out his principle and before applying it to the resolution of the problems, D'Alembert $(1758, p .72)$ wrote that

this principle \& most of the following Problems were included in a Memoir that I read at the Academy towards the end of 1742 [...] The very day on which I began the reading of my Memoir, Mr Clairaut presented another with the title, On some Principles to help solve a large number of Problems in Dynamics; this Memoir, published in the 1742 volume, was read after mine with which, besides, it had nothing whatsoever in common. ${ }^{14}$

This statement confirms that D'Alembert's lectures to the Academy were on his principle and the problems. The chronology shows that his reading was the first, but contradicts the claim that Clairaut began his reading on the same day. Elsewhere, D'Alembert (1743, p. 49) specified that "the greatest Geometers have only identified [...] a very small number of Problems". Are the ones he solves really so different from the ones tackled by Clairaut and his other colleagues?

Tables 1 and 2 present numerous similarities between the problems studied at that time, which tempers somewhat the claim that (Clairaut, 1745) and the Traité have "nothing in common". In addition, Problems IX (Clairaut, 1745) and X (D'Alembert, 1743) are discussed in the correspondence between Euler and Jean Bernoulli (1738); the latter published a solution (Maltese, 1992, pp. 104-110) and Clairaut had been introduced to this type of problem by Daniel Bernoulli. ${ }^{15}$ It was clearly by drawing on all this literature that D'Alembert, elected a member of the Academy on 13 May 1741 and whose initial works apparently were not in the field of dynamics ${ }^{16}$, was able to arrive at a certain number of problems and, in the process, perhaps pursue his own instruction; some publications were afterall contemporaneous to his treatise. D'Alembert (1748, p. 39) confirmed that he knew the works of J. Bernoulli to which he owed "almost all of the little progress I have made in Geometry".

But D'Alembert must also have exchanged ideas with his fellow members of the Academy, as Problem II of the Traité would suggest. In this Problem II, a body moves in a tube in rotation around one of its fixed points on a horizontal plan: the purpose is to find the equation of the curve of the body with regard to the horizontal plan. In the same problem, D'Alembert 
considers too the cases where the tube is in a vertical plan and where it contains several bodies (D'Alembert, 1743, pp. 74-80) ${ }^{17}$. The solution proposed by J. Bernoulli (1742, pp. 248-252) to a problem of this type was only made known in $1743^{18}$; this kind of problems was also the subject of numerous letters exchanged by D. Bernoulli and Euler between March 1742 and February 1744 (Fuss, 1843) but they only published their solution in 1746; D. Bernoulli (1746) also referred to his correspondence with Clairaut. The latter, in response to a lost letter from Euler, mentioned the solutions to Problems III, IV and VI in (Clairaut 1745) and observed that "your problems were not new to me, I had even believed myself to be the first to conceive of them and I gave them to the Academy at the end of last year [in (Clairaut, 1745)]". ${ }^{19}$ D'Alembert did not correspond with J. and D. Bernoulli and the first letter he exchanged with Euler is dated from 3 August $1746 .{ }^{20}$ His interlocutors, then, would have rather been Clairaut, Maupertuis and Fontaine. J. Bernoulli wrote that he had given the two former savants the solution to a problem of this type, though this does not mean that the problem was unknown to them. ${ }^{21}$ Indeed, Fontaine (1740) alluded to some research of this nature undertaken within the framework of celestial mechanics. ${ }^{22}$ It is possible, then, that this type of problem appeared at the Academy independently of any epistolary correspondence: Clairaut (1740a, p. 69v) observed that "the [...] Problem set out by $\mathrm{M}^{\mathrm{r}}$. Fontaine, in which it is supposed that the Body is carried off by a Tube turning at a given speed [...] is rather curious and novel." And as we saw in the letters to Euler mentioned above, Clairaut believed he was the first person to tackle such questions. Consequently, the presence of Problem II in the Traité de Dynamique could be linked to research being carried out at the time within the Academy: either D'Alembert had been informed about the questions raised by J. Bernoulli on this research topic by Maupertuis and/or Clairaut, or he was familiar with the works of Fontaine and/or Clairaut.

The origin of Problem IV in the Traité also deserves to be examined. In this problem, a body $P$ moves along a curve and pulls two bodies by means of two inflexible strings: D'Alembert looks for the speed of $P$ and the equations of the movement of the two bodies (D'Alembert, 1743, pp. 86-95). Maupertuis (1735) resolved Problem II in (Clairaut 1739) (see Table 1) which he said had been presented to him by Koënig; by assuming one of the two masses to be infinite, as Maupertuis does, this problem corresponds to Problem III in (Clairaut 1739) where a body moves along a straight line and pulls only one body by means of a string, a problem which appears in a corollary to Problem IV in D'Alembert (1743). Clairaut and Maupertuis stayed at Bale at the end of 1734 in the company of J. Bernoulli and while there, they met Koënig ${ }^{23}$ : these problems and the methods the two members of the Academy put forward to solve them - using the conservation of vis viva - certainly owed something to these visits. Clairaut $(1739$, p. 1), however, claimed that these types of problems had originally emerged during a disagreement with Fontaine over tractrices and therefore seemed to associate their existence with an academic context.

Beyond the obvious similarities between the kind of problems addressed respectively by Clairaut and D'Alembert (Table 1), the latter's claim that they had "nothing in common" should probably first and foremost be understood as expressing differences of an epistemological order as we will see in the following section. ${ }^{24}$

\section{Academic Context: Principles and Methods}

The Academicians were looking for "some Principles that give the Solution to a large number of Problems in Dynamics" (Clairaut, 1745, p. 1), a "general Method" or "Methods" (Clairaut, 1739, p. 3). They sought to determine the trajectory and velocity of an "infinity of Bodies" (Montigny, 1744), "solve all the questions related to Dynamics using one and the same Method, very simple and direct" (D'Alembert, 1743, p. xxiv), and establish a "general 
principle of dynamics" regardless of how the bodies may act on one another (d'Arcy, 1752, p. 348). Table 1 summarizes the principles and methods employed: what are they?

Clairaut's dynamics is built around the principle of "accelerative forces", which comes back to the fundamental principle of dynamics, and the principle of the conservation of vis viva for an isolated system, the latter being presented in the form of a "theorem" if there are forces external to the system. ${ }^{25}$ The first principle is associated with 1) the principle of inertia that appears via the inertial paths that, free, unattached, the bodies would follow, and 2) the law of action-reaction, implying that the bodies at the end of the inflexible string or rods are subjected to the same degree of tension. Without explicitly presenting such an axiomatic, Clairaut adopts Newton's three laws of motion and extends the object of Newtonian mechanics - the material point - to discrete dynamical systems. In Problem III (Clairaut 1739, p. 11), $P$ is given "an impulse of some kind" and covers the distance $P p$ during a unit of time $d t, M$ crossing the distance $M m$ (Fig. 1). If "the string was suddenly cut", during $d t, P$ and $M$ would cross $P p=p q$ and $m n=M m$ by virtue of their inertial motion. But the action/constraint of the string on $p$ and $m$ prevents $P$ and $M$ from tracing these short lines and "we can consider this action as a force of attraction which acts simultaneously from $p$ towards $m \&$ from $m$ towards $p$, in inverse ratio of their masses"; "the force of the string" will make $P$ travel $p f$ and $M$ travel $m o$, with $p o$ and $m f$ inversely proportional to the mass of the bodies, this in accordance with the law of action-reaction. Clairaut assumes $d t$ is constant and plots an inertial trajectory ( $m n$ during $d t$ without the action of the string) with the tension (which will make mo during $d t$ ) to obtain the curve for $M$ as a succession of segments.

The influence behind such a method is suggested by references to Newton. Clairaut in (1745, p. 21-22) developed a similar technique which he set out in the form of a "general \& direct principle". The physical conditions (inextensible string, inflexible rods), when combined geometrical lemma (Clairaut, 1739, p. 3 and p. $10 ; 1745$, pp. 24-25) can be put into an equation. The lemma, which Fraser (1985) has shown can be interpreted as expressing radial and tangential accelerations in polar coordinates, also feature in D'Alembert (1743, p. 73) who makes explicit reference to Clairaut (1739) and who is probably influenced by this memoir. They allow Clairaut to determine the expressions of mo and $p f$ linked together by the law of action-reaction, which leads him to formulate an equation of the type $\frac{d y}{d t \sqrt{1-y^{2}}}=$ $\frac{p}{\sqrt{m+1-y^{2}}}(K M=y, p$ a constant and $m$ the mass of $P)$; the conservation of the vis viva leads then to an expression of $d t$ which, replaced in the previous equation, finally allows the curve $M$ to be plotted. ${ }^{26}$

Clairaut, then, determines the expressions of forces in linkage conceived as accelerative forces. In (Clairaut, 1738), he takes stock of the forces (forces of constraint, gravity, linkages in the system) acting on each element of a compound pendulum; Clairaut counterbalances these forces in linkage by applying the law of the lever. ${ }^{27}$ In (Clairaut, 1745), he refers to accelerative forces within a non-inertial reference frame (Bertrand, 1848; Bertoloni Meli, 1993), giving him radial accelerations, like those of bodies in rotating tubes, which, in combination with the principle or "theorem" of vis viva leads to the equation of motion.

Although the second principle (conservation of vis viva) can be combined with the first (accelerative forces), it can also be used independently: Clairaut (1740b) deploys it as a variant to the method explained above based on a review of the different forces in linkage. Using this principle, he solves Problem VII (Clairaut 1739) (see Table 1) and underlines that it could also be applied to all the other problems in the memoir. Lastly, in (Clairaut, 1745, $\S \mathrm{X}$, p. 10 ), in regards to a problem that he had been "set by [...] Mr. Jean Bernoulli" - the same as the one in Hermann (1727), Bernoulli (1735) and D'Alembert (1743, pp. 81-86) ; (see Table 1) - and starting from a review of the forces in linkage in an isolated system, Clairaut 
demonstrates that the sum of vis viva is conserved, principle that he establishes as a general rule for all mechanical systems without providing a "general demonstration".

What characterises Clairaut's approach is the use of two methods and the assumption that they are equivalent, one based on the expressions of the linkages in the system, and the other on a conservative principle. However, the demonstration of the conservation of vis viva, since it is based on accelerative forces, would also suggest a hierarchy between the principles. Finally, over the course of his calculations, Clairaut (1745) establishes the conservation and the moment of momentum theorem by combining the principle of accelerative forces and the conservation or "theorem" of vis viva, but without ever conceptualising it.

Montigny analyses Problem VIII in Clairaut (1742) (see Table 1) and generalises it to include any number of objects. Although it was only read in public on 11 and 15 March 1741 in Clairaut's presence, the work was actually composed in $1740 .{ }^{28}$ Montigny makes use of a similar method than Clairaut combining the principle of accelerative forces - a radial acceleration for the bodies attached on an inflexible rod - with the conservation of vis viva, which leads to the conservation of the moment of momentum without it being formulated as a principle. In d'Arcy (1752), the latter is formulated and combined with the conservation of vis viva for the resolutions of the same problem above than Montigny and Clairaut or others problems where d'Arcy looks for the equations of motion of bodies contained in a rotating tube; the problem mentioned in $\S 2$ above (see Table 1). In the works of Montigny and d'Arcy, as with Clairaut, there is always an operation which involves replacing a unit of time $d t$ taken to be constant, with an expression between space and velocity obtained using the principle of vis viva, in order to arrive at a differential equation of motion.

As for D'Alembert, he solves similar problems by recourse to his own principle. D'Alembert's principle is based on breaking down the initial impulses given to a system into components made up of final movements - those having a real impact on the objects depending on the constraints within the system - and other movements which are then destroyed, because in equilibrium: if exposed only to the latter, the system would remain at rest $^{29}$. The conditions for equilibrium acting on these components are the linchpin to obtain the equation of motion, and for this the analysis of the linkages in the system is primordial. This principle combines three others principles - inertia, equilibrium and composition of motion - which D'Alembert demonstrates by criticising the standard proof based on force (Firode, 2001) 3 $^{30}$. The importance of his critical reflexions on causality, his rejection of force (accelerative, vis viva) and his striving to reduce dynamics to a single principle (Le Ru, 1994 ; Firode, 2001 ; Boudri, 2002, pp. 103-135) lead to solutions of an entirely different nature to the ones proposed by his fellow Academicians.

Firstly though, as we have seen, Clairaut also attributes importance to these linkages and the conditions acting on them; Bertoloni Meli (1993, pp. 307-308 and p. 310) claims that this approach is identical to D'Alembert's. However, Nakata (2002) has observed that whereas Clairaut draws up the actions of linkage with inertial tendancies, D'Alembert breaks them down into components, one of which, by virtue of his principle, is found to be in equilibrium; Nakata (2002, p. 30) underlines that "it is rather difficult to understand the meaning of d'Alembert's idea'. The difference seems to be epistemological. D'Alembert attends only to the effects and not to the forces that produced them; the contrary, from his perspective, renders mechanics unintelligible, and its foundations obscure. A contrario, equilibrium results solely from the impenetrability of bodies and their motion. Analysing the problems by attending only to the linkages is tantamount to forging a dynamics based solely on impacts, the fundamental principles of which D'Alembert deduced theoretically (equilibrium, composition). Although such an approach may not clear up questions of causality, studying mechanical interactions founded on impenetrability and equilibrium/constraint is a greater 
source of clarity and intelligibility than Clairaut's composition of forces (Firode, 2001, p. 133).

Then, D'Alembert does not posit a time constant $d t$ in his calculation of trajectories. Fraser (1985, pp. 50-51), who does not explain anymore than Nakata (2002, p. 30) the reasons behind this omission, relays Lagrange's criticism of this practice for "complicating" the calculations. D'Alembert asserted his decision not to posit " $d t$ or a constant interval of time, in order to formulate the Equation of the Curve without determining the expression of velocity, which would be necessary if we made $d t$ constant, as $d t$ is $\frac{d x}{u}$, we can only substitute $d t$ once we know the value of $u$ " and pursued his argument by specifying that $u$ could be obtained "by different means", but this would not be necessary if one uses the method he proposes (D'Alembert, 1743, p. 77). ${ }^{31}$ This refusal of a " $d t$ constant" can notably be found in D'Alembert's examination of Problem IV of his Traité. His method could be interpreted as the rejection of a technique, much in use at the Academy, calling for an additional principle, one formulated by Clairaut, Montigny and also d'Arcy, based on this time constant $d t$ which they replace by an expression obtained through the conservation of vis viva.

On the one hand, D'Alembert rejects the use of the principle of accelerative forces, and, in the final analysis, of a Newtonian type method in which the combination of forces with inertial motion plays a key role; on the other, he rejects certain principles on the grounds that they lack clarity (because linked to causality) and cannot be generalised. Hence, the conservation of vis viva only applies to elastic collisions or continual actions that do not collide with hard bodies (D'Alembert, 1757, pp. 115a-115b) and the principle formulated by d'Arcy (1752), namely the conservation of the moment of momentum, must be combined with another principle. These principles can be useful in abridging calculations, but D'Alembert qualifies them as "secondary" and not "primordial" for the principal reason that "the metaphysics" behind them "will never be clear" (D'Alembert, 1755a, pp. 175b-176a).

According to D'Alembert (1755b, pp. 492b), principles must be presented in conformity with a "metaphysics of propositions" or assertions, in other words, with "the clear and precise presentation of general and philosophical truths on which all scientific principles are based"; it is a question of "general principles on which each science is based, \& which, like seeds of particular truths, it covers and must expose" (D’Alembert, 1767, p. 255). The geometer calls for a "simple" metaphysics, presenting principles that are "clear" and "tangible" illustrated, in mechanics, by "the impenetrability of bodies, at the origin of their reciprocal action". $\mathrm{He}$ evokes the existence of "common and primordial notions", beyond dispute, on which all men agree and which could underpin a science (D'Alembert 1755b, pp. 492a-493a; 1759, pp. 2729). This would apply to space and time, the combination of which provides a definition of motion, the principle object of mechanics, whereas a "contentious and opaque Metaphysics" on the nature of motion is "foreign to this science" (D'Alembert 1755b, p. 493a, p. 494b ; 1759 , p. 27-29). D'Alembert states his aim is to "neutralise", through rigorous definition, any meaning other than scientific of certain concepts and principles (Le Ru 1994, p. 107-110), thereby imparting to mechanics "an intangible and timeless conceptual framework" by forging primordial notions common to all men and rendering definitions unchanging, definitive (Firode 2001, p. 82-84). The certitude of mechanical science and its deductive structure are based on "common notions" of space and time, and on the mathematical definition of motion, the impenetrability of bodies and the principles which these notions give rise to: clear principles, reduced to their smallest possible number, conditions which guarantee their fecundity (D'Alembert 1743, p. ij-iij). D'Alembert excludes from mechanics principles judged to be obscure or unuseful, and although the conservation of vis viva does appear in his Traité, it is only after having been demonstrated using the principle of D'Alembert (1743, p. 169-186), which results in this conservation being relegated to the status of a "secondary" principle in the axiomatic framework of dynamics. ${ }^{32}$ 
In the Problem II of his Traité33, D'Alembert (1743, pp. 79-80) alludes to the "true Metaphysics of the Problem", specifying that the solution is founded on a "difference between two forces": one which would move the body at a given speed were it free, and another which moves the body linked to the system at the same speed. ${ }^{34}$ In other words, the difference between an initial force (which assumes that "all the other bodies [in the system] have been eliminated") and a final force (obtained once part of the initial force has been spent "overcom[ing] the action of these same Bodies"). This difference is the quantity of force counterbalanced by virtue of D'Alembert's principle. It is indeed a "true Metaphysics" to the extent that the principle is founded on "true Principles of the thing", in other words the physical nature of the bodies - their impenetrability - and their related principles - inertia, equilibrium and composition of motion.

\section{Conclusion}

Truesdell (1960, p. 188; 1968, p. 164) underlines "the intricacy of [D'Alembert's] method" and considers "obscure his statements and procedures"; he also refers to (1968, p. 249 et p. 262) "the D'Alembert-Euler principle", seeing a form of D'Alembert's principle in Euler (1740). (D'Alembert 1743, p. 72) refers to Euler's method (1740), but is critical of the lack of demonstration and its limited application to only a few problems ${ }^{35}$. These aspects demonstration of a principle, the full scope of what it can be applied to - are part of this "metaphysics of assertions" which contributes to the axiomatic framework of dynamics and betters our understanding of the choices behind his proposed solutions that we could only partially interpret if we confined our reading to the technical aspects. ${ }^{36}$ D'Alembert (1743, pp. 76-77, pp. 79-80) acknowledged the lengthiness of his method and the existence of other more elegant and expeditive ones, but he sought to inscribe the science of mechanics into this "metaphysics of assertions" which, we could add, implies a "metaphysics" of problemsolving.

Between the works of D'Alembert and those of his fellow members of the Academy, there are a number of points in common. Firstly, some of the problems featured in the Traite de dynamique appear to have originated in an academic context, which raises the question of D'Alembert's relations with his colleagues and, faced with a lack of source material on his formative years, thereby opens up new roads of enquiry. Then, the solutions to different problems presented by both Clairaut and D'Alembert hinge on intrinsic coordinates for mechanical systems, in our case polar coordinates, and the "accelerative forces" - namely, radial and tangential components of acceleration expressed in polar coordinates - are calculated on a case-by-case basis depending on the type of system: neither savant formulated general analytical expressions for these forces. ${ }^{37}$ In addition, the principle of "accelerative forces" is not formulated in Cartesian coordinates. ${ }^{38}$ Lastly, the moment of momentum theorem and its conservation were not truly conceptualised before d'Arcy (1752), although this conservation does appear in D'Alembert (1743). ${ }^{39}$ However, by taking on major epistemological challenges which had a determining effect on his problem-solving methods, D'Alembert's project in the field of dynamics had "nothing in common" not only with the works of his fellow academicians, but, more generally, with those of the other savants celebrated in his day. 


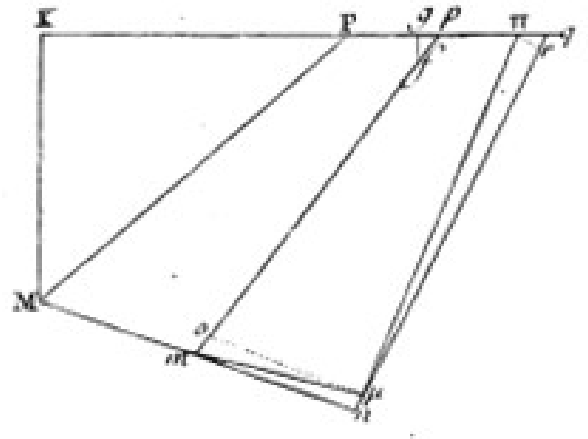

Fig. 1 : Clairaut (1739, p. 22) 


\begin{tabular}{|c|c|c|c|c|c|c|}
\hline & Maupertuis & Clairaut & Fontaine & Montigny & D'Alembert & d'Arcy \\
\hline $\begin{array}{l}\text { Bodies joined by an inflexible } \\
\text { string on a horizontal plane }\end{array}$ & $\begin{array}{l}1735 \\
\mathbf{V V}\end{array}$ & $\begin{array}{l}\text { Pb II (Solution III) (1739) } \\
\text { VV }\end{array}$ & & & & \\
\hline $\begin{array}{l}\text { Compound pendulum in a } \\
\text { constrained system (rod) : }\end{array}$ & & $\begin{array}{l}\mathrm{Pb} \text { I et II }(1740 \mathrm{~b}) \\
\text { AF+the law of the lever } \\
\text { VV }\end{array}$ & & & Pb I, Corollaire I (1758) DAP & \\
\hline Compound pendulum (string) & & $\begin{array}{l}\mathrm{Pb} \text { VII (1739) } \\
\mathbf{A F + V V}\end{array}$ & & & $\mathrm{Pb} \mathrm{V}(1743,1758)$ DAP & \\
\hline $\begin{array}{l}\text { Mobile(s) in a rotating tube on a } \\
\text { vertical or horizontal plane }\end{array}$ & & 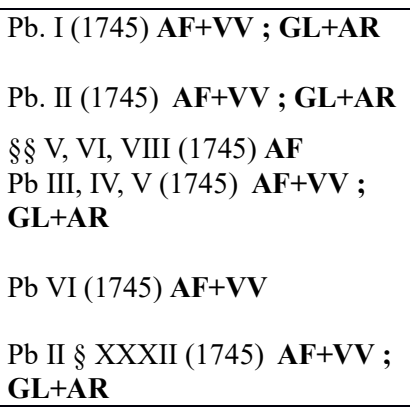 & $\mathbf{A F}$ & & $\begin{array}{l}\mathrm{Pb} \text { II }(1743,1758) \text { DAP+GL } \\
\mathrm{Pb} \text { II, Rem. II }(1743,1758) \text { DAP+GL } \\
\mathrm{Pb} \text { II, Rem. III }(1743,1758) \text { DAP+GL } \\
\mathrm{Pb} \text { II, Rem. IV (1758) DAP+GL } \\
\mathrm{Pb} \text { II, Rem. IV (1743), Rem. V (1758) } \\
\text { DAP+GL } \\
\mathrm{Pb} \text { II, Rem. VII (1758) DAP+GL }\end{array}$ & $\mathrm{Pb}$ I MM+VV \\
\hline $\begin{array}{l}\text { Motion of two bodies on two } \\
\text { adjacent lines connected by a } \\
\text { string over a pulley }\end{array}$ & & $\S X(1745) \mathbf{A F}$ & & & Pb III, Cor. IV $(1743,1758)$ DAP & \\
\hline $\begin{array}{l}\text { Body/ies towed in a groove by } \\
\text { another moving body }\end{array}$ & $\begin{array}{l}1735 \\
\text { VV }\end{array}$ & $\begin{array}{l}\mathrm{Pb} \text { III (1739); Pb. X (1745) } \\
\text { GL+VV; AF+VV }\end{array}$ & & & $\begin{array}{l}\text { Pb IV, Cor. I et II }(1743,1758) \\
\text { DAP+GL }\end{array}$ & \\
\hline $\begin{array}{l}\text { Bodies in motion on a moving } \\
\text { plane }\end{array}$ & & $\mathrm{Pb}$ IX (1745) AF+VV ; AR & & & $\mathrm{Pb} \mathrm{X}(1743,1758)$ DAP & $\mathbf{A R}$ \\
\hline $\begin{array}{l}\text { Bodies mounted on an inflexible } \\
\text { rod rotating around a fixed ring } \\
\text { into which it can slide }\end{array}$ & & $\mathrm{Pb}$ VIII (1745) GL+AR & & $\mathbf{A F}+\mathbf{V V}$ & & $\mathrm{Pb}$ II $\mathbf{M M + V V}$ \\
\hline $\begin{array}{l}\text { Tube moving around a fixed } \\
\text { point and containing a body }\end{array}$ & & $\mathrm{Pb} \mathrm{XI}(1745) \mathbf{G L}+\mathbf{A R}$ & & & & $\begin{array}{l}\mathrm{Pb} \text { III } \\
\mathbf{M M + V V}\end{array}$ \\
\hline
\end{tabular}

Table 1: Correspondence between problems in dynamics tackled by Academicians with the type of principles they applied in bold: (Problem (Pb); principle of accelerative forces (AF); principle of vis viva (VV); D'Alembert's principle (DAP); AR (action-reaction); MM (moment of momentum theorem or conservation of the moment of momentum); GL (geometric lemma of acceleration in polar co-ordinates). In these problems it must be found the curves, the speeds or the differentials equations of motions of the bodies after initials impulses given to the mechanical system i.e. the strings, rods, tubes etc. which connect the bodies together. 


\begin{tabular}{|c|c|c|c|c|c|c|c|}
\hline & $\mathrm{Pb} \mathrm{I}$ & $\begin{array}{c}\mathrm{Pb} \text { II and } \\
\text { Geometric } \\
\text { Lemma }\end{array}$ & $\mathrm{Pb}$ III & $\mathrm{Pb} \mathrm{V}$ & $\mathrm{Pb} \mathrm{VII}{ }^{40}$ & $\mathrm{~Pb} \mathrm{XII}{ }^{41}$ & $\mathrm{~Pb} \mathrm{XIV}{ }^{42}$ \\
\hline J. Bernoulli & 1717 & & 1729 & & & & 1727 \\
\hline Hermann & & & 1729 & & & & \\
\hline Clairaut & & 1739 & & & & & \\
\hline Euler & 1740 & & & 1741 & 1740 & & \\
\hline D. Bernoulli & & & & 1738,1740 & & & \\
\hline J. (II) Bernoulli & & & & & & 1740 & \\
\hline MacLaurin & & & & & & & 1742 \\
\hline Bouguer & & & & & & & 1728 \\
\hline
\end{tabular}

Table 2: Savants mentioned in the fourteen problems in D'Alembert (1743) 


\section{NOTES}

1. Clairaut, writing to Euler on 7 December 1743, said he had "given up this subject since the beginning of the year" (Juškevič, Taton, 1980, pp. 146-147). (Montigny, 1744) is the only essay this savant wrote on these problems; Montigny presents his essay at the Academy in 1741, see RMAS (11 and 15 March 1741). (d'Arcy, 1752) features an overview of the methods developed mostly in (Clairaut, 1745) and includes a text read aloud at the Academy in 1743, see RMAS (24 July 1743, p. 333). (D’Alembert, 1758) sheds some light on the solutions given in (D'Alembert, 1743). In order to respect this homogeneity in the problems being studied, we have excluded from our corpus (Maupertuis 1742; 1748). Texts read at the Academy can be much later published; our article studies debates mainly take place internally at the Academy and so the most important dates are more the dates of reading than those of publication.

2. On the appearance of the word "dynamics" at the Academy, see (Ariga, 2013). On the emergence of this field and the division of mechanics into statics and dynamics, see (Schmit, 2014; 2015).

3. See notably, (Truesdell, 1960; 1968), (Bos, 1980), (Maltese, 1992), (Bertoloni Meli, 1993).

4. (Maltese, 1992, pp. 113-120), (Bertoloni Meli, 1993, pp. 307-310) and (Nakata, 2002, pp. 19-32) analyse Clairaut's first principle and/or the first problem (Clairaut, 1745); Bertrand (1848), Truesdell (1960, pp. 222-223) and Bertoloni Meli (1993) draw attention in Clairaut's memoir to the use of force in référentiels mobiles. (Maltese, 1992, p. 120-122) analyse a problem set out by d'Arcy (1752). The work of Maupertuis (1735), Fontaine (1740) and Montigny (1744) have not been the subject of research.

5. See notably, Fraser (1985), Vilain (2000), Firode (2001), Nakata (2002), Viard (2002).

6. Nakata (2002) would seem to be the only exception, but his study focuses solely on a comparison between D'Alembert and Clairaut based on two problems.

7. (Bernoulli 1742) is not exclusively concerned with dynamics.

8. In a chapter devoted to movements on mobile surfaces, Maltese (1992) does not study D'Alembert's (1743) responses to this question. Truesdell (1968, pp. 111-113) only mentions Clairaut's work on the figure of the Earth, and restricts D'Alembert's (1743) contribution to the appearance of the "earliest differential equations of motion for systems", as does Maltese (1992, pp. 148-165).

9. For these readings, see RMAS (24 November 1742, p. 424; 28 November 1742, p. 436; 1 December 1742 , p. 437; 5 December 1742, p. 438; 15 December 1742, p. 457; 9 February 1743, p. 103; 16 February 1743, p. 111; 23 February 1743, p. 117; 27 February 1743, pp. 123-124). Clairaut was present throughout.

10. RMAS (23 December 1740, p. 230r; 23 December 1741, p. 489).

11. RMAS (22 December 1742, p. 461; 2 March 1743, p. 151; 13 March 1743, p. 164; 16 March 1743, p. 168; 20 March 1743, p. 184; 23 March 1743, p. 185; 30 March 1743, p. 199; 3 April 1743, p. 201; 6 April 1743 , p. 204). D'Alembert was absent on 20 and 23 March, as well as on 3 April. Neither he, nor Montigny were marked present on 6 April even though they were reading a report.

12. (RMAS, 6 March 1743, pp. 123-124).

13. (D'Alembert, 1743) corresponds to a quarto format comprising 186 pages and 4 plates, of which the second part makes up 137 pages. Assuming that the "12 little notebooks" were in quarto, that would give us 96 handwritten pages that could correspond to this part.

14. These lines do not feature in the 1743 edition.

15. As Clairaut tells Euler on 15 July, 1742 (Juškevič, Taton, 1980, p. 136). In Problems IX in (Clairaut, 1745, p. 41) and $X$ in (D'Alembert, 1743, pp. 141-142) a body falls on an inclined plan which can have also a rectilinear movement on a horizontal surface: the problem is to find the motions of the body and of the inclined plan. For an analysis of D'Alembert's solution see (Fraser, 1985).

16. Research conducted in the fields of mathematics (Gilain, 2007) and fluid mechanics RMAS (6 February and 20 July 1740, pp. 19r-19v and pp. 155r-155v; 2 August and 16 August 1741, pp. 369-404 and pp. 424-438; 17 March and 24 July 1742, pp. 126-133 and pp. 349-356).

17. For a detailed analysis of this problem and a detailed comparison between D'Alembert's solution and the solutions in Clairaut and Euler, see (Fraser 1985) and (Nakata, 2002). For the same problem in J. and D. Bernoulli, in Clairaut, and in Euler, see (Maltese, 1992).

18. Although the year 1742 is inscribed on the first page of the volumes of (Bernoulli 1742), the first volume contains a letter from J. Bernoulli dated 9 January 1743, a "Editor Lectori" (editorial letter addressing the reader) which ends "Vale. Dabam Genevæ, Cal. Mart. 1743" with two engravings from 1743. We would like to thank N. Guicciardini for having drawn our attention to the "Editor Lectori" and one of the engravings.

19. Clairaut to Euler, 7 September 1743, (Juškevič, Taton, 1980, pp. 149-150). In Problem III, the tube moves in a horizontal plan and contains two bodies in movement: Clairaut looks for the equation of motion of the tube. In Problem IV, under the same hypotheses, he gives the trajectories of both bodies. In Problem VI, there is any 
number of bodies and Clairaut finds the movement of the tube in a horizontal plan. See (Clairaut, 1745, pp. 3037).

20. Passeron $(2009 ; 2015)$.

21. Problem set by Samuel Koënig to Bernoulli. Bernoulli to Euler, 15 March and 27 August 1742 (Fuss, 1843, pp. 67-71 and pp. 72-81).

22. The analyses presented by Fontaine (1740) contained an error detected by Clairaut and corrected in the same volume (Fontaine 1740). (Fontaine 1764, pp. 319-321) reproduces this study. There was a colloquium on Fontaine in Cuiseaux (Saône-et-Loire, France) on September $3^{\text {rd }}$ and $4^{\text {th }} 2004$ but the acts are not published. Ryoichi Nakata and Jérôme Viard gave two talks on Fontaine's mechanics.

23. As testified by Koënig's letter to Maupertuis dated 27 January 1739 (Le Sueur, 1896, p. 110-111).

24. D'Alembert will have later bad relations with Clairaut and Fontaine but we have no documents for this period which could give indications.

25. The first would correspond to the proportion between a given force and the acceleration produced; the second to the conservation of kinetic energy in an isolated system and, in the presence of forces external to the system, to the theorem of kinetic energy.

26. By the conservation of vis viva $m\left(\frac{P p}{d t}\right)^{2}+\left(\frac{M m}{d t}\right)^{2}=A$ with $A$ as a constant, $m$ and 1 the mass of $P$ and $M$.

27. Both the problem and the technique deployed to solve it are identical in Bernoulli (1742, t. 4, p. 382-386).

28. See (RMAS, 11 and 15 March 1741, p. 82 and p. 86).

29. D'Alembert gives his principle as a "method very simple and very direct" which could solve "all the questions of dynamics": "decompose motions $a, b, c \& c$. given to bodies by initials impulses each in two others motions $\mathrm{a}, \alpha ; \mathrm{b}, \beta ; \mathrm{c}, \chi ; \& \mathrm{c}$. of such kind as if we gave only to the bodies a, b, c \&c. they could keep these motions without interacting together; and if we gave only $\alpha, \beta, \chi, \& \mathrm{c}$. the system of bodies would stay at rest; it is clear that a, b, c \&c. will be the finals motions the bodies will have because of theirs mutual actions". See (D'Alembert, 1743, p. xxiv and p. 50).

30. These three principles are also called "laws" or "theorems". The first principle contains two laws: the first one deals with bodies at rest which stay at the same state until a force acts on them, the second one that a body pushes in motion keep a rectilinear motion with the same speed without others forces. The second principle is the compound motion of two or several impulses acting on one body i. e. what could be called the parallelogram of forces. The last principle concerns equilibrium between two hard bodies which collide: if they have the same momentum in an opposite direction they are said to be in equilibrium. See (D'Alembert, 1743, pp. 3-4; p. 22; p. 37).

31. With $d x$ as the distance covered during $d t$ at velocity $u$.

32. D'Alembert (1743, p. 169-186) calculates the conservation of vis viva with the help of his principle. D'Alembert (1757, pp. 115a-115b) suggests that he reads his demonstration at the Academy when he presented his Traité in 1742 and 1743. He writes that he gives in his Traité a demonstration "in all cases" and (Clairaut 1745) demonstrates it "in a particular way"; he writes too that he is the first to prove the conservation of vis viva for hydrodynamics see (D'Alembert, 1757). There is no demonstrations of this principle in (Montigny 1741), (d'Arcy, 1752) and (Fontaine, 1740; 1764).

33. D'Alembert supposes a body in a rotating tube and that the law of rotation of the tube is given; he looks for the curve of the body. See (D'Alembert, 1743, p. 78-80).

34. Unfortunately, due to the lack of space, we cannot give here an analysis of Problem II. For a detailed study of this problem, see (Fraser, 1985) and (Nakata, 2002).

35. (Euler, 1740) deals with compound pendulums and small oscillations of rigid or flexible bodies, see (Truesdell, 1960, p. 167-170) and (Vilain 2000). In order to find the length of a simple pendulum isochronal to a compound pendulum, Euler considers that the reversed final accelerations of the bodies of the compound pendulum are equipollent to the initials impulses per unit of mass given to these bodies. D'Alembert uses this method but only after having proved it by his principle as formulated in his Traité (1743) and so only in taking into account the physical nature of bodies and their laws which are demonstrated, see (D'Alembert, 1749, pp. 3536). On the differents formulations of D'Alembert's principle, see (Fraser, 1983, pp. 223-225) and (D'Alembert, 2006, pp. 101-103 and notes 86-89).

36. It would be impossible to sum up the origin of D'Alembert's principle if it is apprehended merely as the generalisation of a pre-existing mathematical method, as it is in (Truesdell, 1960, p. 191).

37. On the systematic use by Euler and Clairaut of these analytical expressions in polar coordinates in the field of celestial mechanics from 1747 onwards, see Bertoloni Meli (1993, pp. 314-318).

38. On Euler's use of accelerative forces expressed in cartesian coordinates, see Truesdell (1960, pp. 250-253 ; 1968, pp. 167-171), Bertoloni Meli (1993, pp. 315-316).

39. Note that this theorem and its conservation are in large measure applied to discrete and discontinuous dynamical systems. According to Truesdell (1968, note 14, p. 248), the Traité de dynamique «contains no 
allusion to moment of momentum, torque, or the area integral, although Chapters II and IV of the Seconde Partie concern the integrals of momentum and energy, respectively »; Viard (2002) invalidates this commentary.

40. Study of the movement of a body that sways on a horizontal plane.

41. Analysis of the velocity of two bodies attached to the ends of two rods rotating around their free extremities at the moment of their collision.

42. Calculation of a body's final velocity, a moving body colliding simultaneously with others at rest.

Abbreviations

\section{REFERENCES}

HARS 17XX : Histoire de l'Académie royale des sciences, année 17XX (Paris : Imprimerie royale).

RMAS 17XX : Registres manuscrits de l'Académie royale des sciences, année 17XX

CASP 17XX: Commentarii Academice Scientiarum Imperialis Petropolitance, 17XX (Petropoli : typis academiæ)

Ariga, N. (2013) The emergence of the dynamique in the Paris academy of sciences, Recueil d'études sur l'Encyclopédie et les Lumières, 2, 2013, 243-257.

Bernoulli, D. (1738) Theoremata de oscillationibus corporum filo flexili connexorum et catenæ verticaliter suspensæ, CASP 1732-1733, 108-122.

Bernoulli, D. (1740) Demonstraniones Theorematum suorum de oscillationibus corporum filo flexili connexorum catenæ verticaliter suspensæ, CASP 1734-1735, 162-173.

Bernoulli, D. (1746) Sur un nouveau problême de Mechanique, Histoire de l'Académie royale des sciences et des belles lettres de Berlin, Année 1745 (Berlin : Haude), 54-70.

Bernoulli, J. (1717) Nouvelle Theorie du Centre d'Oscillation, HARS 1714, 208-230.

Bernoulli, J. (1727) Discours sur les loix de la communication du mouvement (Paris : Jombert)

Bernoulli, J. (1729) Theoremata selecta pro conservatione virium vivarum demonstranda et experimentis confimanda, CASP 1727, 200-207.

Bernoulli, J. (1735) De vera notione virium vivarum ; earumque usu in Dynamicis, Nova Acta Eruditorum, Mai 1735, 210-230.

Bernoulli, J. (II) (1740) De motu corporum se inuicem percutientium, CASP 1734-1735, 15-34.

Bernoulli, J. (1738) Solutiones novorum quorundam Problematum Mechanicorum, CASP 1730-1731, 11-25.

Bernoulli, J. (1742) Opera omnia (4 t.) (Lausanne, Genève : Bousquet).

Bertoloni Meli, D. (1993) The emergence of reference frames and the transformation of mechanics in the Enlightenment, Historical Studies in the Physical and Biological Sciences, 23 (2), 301-335.

Bertrand, J. (1848), Note sur la théorie des mouvements relatifs, Journal de l'Ecole polytechnique, 19, 179-154.

Bos, H. J. M. (1980) Mathematics and rational mechanics, in : G. S. Rousseau, R. Porter (ed.) The Ferment of Knowledge (Cambridge : Cambridge University Press), pp. 327-355.

Boudri, J. C. (2002) What Was Mechanical about Mechanics (Dordrecht : Kluwer Academic Publishers).

Bouguer, P. (1728) Solution, par les seules regles ordinaires de la communication des mouvemens, du Problême de M. Bernoulli, sur le choq d'un corps qui en rencontre plusieurs autres qui sont en repos, Journal des Savans, (avril), 232-237.

Clairaut, A.-C. (1739) Solution de quelques problèmes de Dynamique, HARS 1736, 1-22.

Clairaut, A.-C. (1740a) Plusieurs Solutions du Probléme où il s'agit de déterminer l'Orbite d'un Corps, qui est sollicité continuellement vers un Centre, RMAS, Samedi 2 avril, 66v-71v.

Clairaut, A.-C. (1740b) Des Centres d'Oscillation dans des Milieux résistants, HARS 1738, 159-168.

Clairaut, A. (1745) Sur quelques principes qui donnent la Solution d'un grand nombre de Problèmes de Dynamique, HARS 1742, 1-52.

D’Alembert, J. Le Rond (1743) Traité de dynamique (Paris : David l'aîné)

D’Alembert, J. Le Rond (1748) Mémoire historique sur la vie \& les ouvrages de M. Jean Bernoulli, Mercure de France, 3, 39-78.

D’Alembert, J. Le Rond (1749) Recherches sur les précession des équinoxes et sur la nutation de l'axe de la Terre dans le systême newtonien (Paris : David l'aîné)

D’Alembert, J. Le Rond, (1755a), Dynamique, Encyclopédie, t. V (Paris : Briasson, David l'aîné, Le Breton, Durand), 174a-176a.

D’Alembert, J. Le Rond (1755b) Elémens des sciences, Encyclopédie, t. V (Paris : Briasson, David l'aîné, Le Breton, Durand), 491a-497a.

D’Alembert, J. Le Rond (1757) Conservation des forces vives, Encyclopédie, t. V (Paris : Briasson, David l'aîné, Le Breton, Durand), 114b-116b.

D’Alembert, J. Le Rond (1758) Traité de dynamique (Paris : David). 
D’Alembert, J. Le Rond (1759) Mélanges de littérature, d'histoire et de philosophie, t. IV (Amsterdam : Zacharie Chatelain \& fils).

D’Alembert, J. Le Rond (1767) Mélanges de littérature, d'histoire et de philosophie (Amsterdam : Zacharie Chatelain \& fils).

D’Alembert, J. Le Rond (2006), Précession et nutation (1749-1752), Euvres complètes, vol. I/7, M. ChaprontTouzé and J. Souchay (ed.) (Paris: CNRS Editions).

D’Arcy, P. (1752) Problème de Dynamique, HARS 1747, 344-361.

Euler, L. (1740) De minimis oscillationibus corporum tam rigidorum quam flexibilium, CASP 1734-1735, 99122.

Euler, L. (1741) De Oscillationibus fili flexilis quotcunque pondusculis onusti, CASP 1736, 30-47.

Euler, L. (1746) Opuscula varii argumenti (Berlin : Haube, Spener).

Firode, A. (2001) La dynamique de D'Alembert (Paris, Montréal : Vrin, Bellarmin).

Fontaine des Bertins, A. (1740) Probléme. La loy de la force Centrale, le lieu d'où part un Corps, sa vitesse et sa direction étant données, trouver son mouvement dans l'Espace, RMAS, 16 mars 1740, 62v-64v.

Fontaine des Bertins, A. (1764) Mémoires données à l'Académie royale des sciences, imprimés dans leur temps (Paris : Imprimerie royale).

Fraser, C. (1983) J. L. Lagrange's Early Contributions to the Principles and Methods of Mechanics, Archives for the History of Exact Sciences, vol. 28, n 3, pp. 197-241.

Fraser, C. (1985) D'Alembert's Principle : The Original Formulation and Application in Jean d'Alembert's Traité de Dynamique (1743), Centaurus, 28(1, 2), 31-61 and 145-159.

Fuss, P.-H. (1843) Correspondance mathématique et physique de quelques célèbres géomètres du XVIII siècle, t. II, (St. Pétersbourg : Académie Impériale des sciences).

Gilain, C. (2007) Textes de mathématiques pures (1745-1752), Euvres complètes de Jean Le Rond D'Alembert, vol. I/4a (Paris : CNRS éditions).

Hermann J. (1729) Theoria generalis motum, CASP 1727, 139-173.

Juškevič, A., Taton, R. (1980) Leonhardi Euleri Commercium Epistolicum, Opera Omnia, IVa (5) (Bâle : Birkhäuser).

Le Sueur, A. (1896) Maupertuis et ses correspondants (Genève : Slatkine reprints)

MacLaurin, C. (1742) Treatise of fluxions (Edinburgh : Ruddimans).

Maltese, G. (1992) La storia di " $F=m a$ ” (Firenze : Olschki).

Maupertuis, P.-L. Moreau de (1735) Probléme Dynamique proposé par Mr Koënig, RMAS, Mercredi 4 mai, $107 \mathrm{v}-108 \mathrm{v}$.

Maupertuis, P.-L. Moreau de (1742) Loix du Repos des Corps, HARS 1740, 170-177.

Maupertuis, P.-L. Moreau de (1748) Accord de différentes loix de la Nature qui avoient jusqu'ici paru incompatibles, HARS 1744, 417-426.

Montigny, E. Mignot de (1744) Problèmes de dynamique où l'on détermine les Trajectoires \& les vîtesses d'une infinité de Corps mis en mouvement autour d'un centre immobile, HARS 1741, 280-291.

Nakata, R. (2002) The General Principles for Resolving Mechanical Problems in d'Alembert, Clairaut and Euler, Historia Scientiarum, 12(1), 18-42.

Passeron, I. (2009) Inventaire analytique de la correspondance, Euvres complètes de Jean Le Rond D'Alembert, vol. V/1 (Paris : CNRS éditions).

Passeron, I. (2015). Correspondance générale (1741-1752), Euvres complètes de Jean Le Rond D'Alembert, vol. V/2 (Paris : CNRS éditions).

Schmit, C. (2014; 2015) Méchanique, Statique, Dynamique. Répartition du savoir et définitions dans l'Encyclopédie, Recherches sur Diderot et sur l'Encyclopédie, 49, 224-258 and 50, 273-299.

Truesdell, C. (1960) The rational mechanics of flexible or elastic bodies 1638-1788. Introduction to L. Euleri Opera Omnia, vol. X-XI, II (Turin : Füssli).

Truesdell, C. (1968) Essays in the History of Mechanics (Berlin, Heidelberg, New York : Springer Verlag).

Viard, J. (2002) Le principe de D'Alembert et la conservation du moment cinétique d'un système de corps isolés dans le Traité de dynamique, Physis, 39, 1-40.

Vilain, C. (2000) La question du centre d'oscillation de 1660 à 1690, Physis, 37, 21-51.

Vilain, C. (2000) La question du centre d'oscillation de 1703 à 1743, Physis, 37, 439-466. 